\title{
Clinical and molecular characterization of seven patients with Danon disease
}

\author{
XUAN-YING WANG ${ }^{1,2^{*}}$, BO WANG $^{1^{*}}$, XIAO-LI ZHU ${ }^{1 *}$, ZHI-LING MA $^{3}$, YING LIU $^{4}$, CHANG-HUI LEI $^{1}$, \\ QIAN-LI YANG ${ }^{1}$, DAN HU ${ }^{5,6}$, XUE-LI ZHAO ${ }^{1}$, ZHI-RONG LIU $^{2}$ and LI-WEN LIU ${ }^{1}$ \\ ${ }^{1}$ Department of Ultrasound, Xijing Hypertrophic Cardiomyopathy Center, Departments of ${ }^{2}$ Neurology, \\ ${ }^{3}$ Cardiology and ${ }^{4}$ Radiology, Xijing Hospital, Fourth Military Medical University, Xi'an, Shaanxi 710032; \\ ${ }^{5}$ Department of Cardiology and Cardiovascular Research Institute, Renmin Hospital of Wuhan University; \\ ${ }^{6}$ Hubei Key Laboratory of Cardiology, Wuhan, Hubei 430060, P.R. China
}

Received February 4, 2020; Accepted July 27, 2020

DOI: $10.3892 /$ etm.2021.9826

\begin{abstract}
Danon disease is an X-linked glycogen storage disease characterized by skeletal myopathy, cardiomyopathy and intellectual impairment. It is caused by a loss-of-function mutation in the lysosome-associated membrane protein-2 (LAMP2) gene. In the present study, exon and boarding intron analysis of 96 cardio disease-associated genes was performed in 770 patients with hypertrophic cardiomyopathy (HCM) using second-generation sequencing. Next, the identified mutations were confirmed in family members of the patients and 300 healthy controls. Detailed clinical, electrocardiographic (ECG) and echocardiographic findings were recorded. A pathogenic mutation in LAMP2 was identified in 7 patients who phenotypically presented with HCM. A total of four patients had a fragmented QRS complex (fQRS) on surface ECG. In addition, two patients presented with ventricular preexcitation with a short PR interval. Compared with the patients with protein kinase AMP-activated non-catalytic subunit $\gamma 2$ syndrome and Fabry disease, the 7 patients with Danon disease presented at an earlier age, had a smaller left atrial size, a thinner maximal left ventricular wall thickness and a lower probability of pacemaker implantation. Compared with 12 sex- and age-matched patients with sarcomere-protein mutations, the 4 patients with Danon disease had a lower left ventricular outflow tract gradient and worse diastolic function.
\end{abstract}

Correspondence to: Professor Li-Wen Liu, Department of Ultrasound, Xijing Hypertrophic Cardiomyopathy Center, Xijing Hospital, Fourth Military Medical University, 127 Changle West Road, Xi'an, Shaanxi 710032, P.R. China

E-mail: liuliwen@fmmu.edu.cn

Professor Zhi-Rong Liu, Department of Neurology, Xijing Hospital, Fourth Military Medical University, 127 Changle West Road, Xi'an, Shaanxi 710032, P.R. China

E-mail: liuzhir@fmmu.edu.cn

Key words: Danon, fragmented QRS complex, lysosomal-associated membrane protein 2 , genetic analysis, hypertrophy, left ventricle
The present study provided a comprehensive comparison of different pathologies presenting with HCM and reported on features of early-onset Danon disease, including the characteristic preexcitation and fQRS on ECG. This may provide valuable information that may be utilized for the early diagnosis and treatment of patients with Danon disease. The present study was registered as a clinical trial with ClinicalTrials.gov (Sep. 2, 2016; registry no. NCT02888132).

\section{Introduction}

Danon disease was first described as a 'lysosomal glycogen storage disease with normal acid maltase' by Danon et al (1) in 1981. They reported on two young, unrelated males with mental retardation, cardiomyopathy and proximal myopathy, who exhibited apparently generalized glycogenosis with no demonstrable enzyme defect. In 2000, Nishino et al (2) concluded that a primary deficiency of lysosome-associated membrane protein-2 (LAMP2) led to Danon disease. LAMP2 is a lysosomal structural protein that is essential to the autophagy process. LAMP2-deficient mice exhibit extensive accumulation of autophagic vacuoles in several tissues (3), and hepatocytes that lack LAMP2 exhibit similar accumulation of autophagosomes (4). Therefore, biopsies frequently contribute to the diagnosis of Danon disease; however, they are neither necessary nor diagnostic. Similar vacuoles may also be encountered in other metabolic diseases, such as protein kinase AMP-activated non-catalytic subunit $\gamma 2$ (PRKAG2) syndrome and Fabry disease (5).

Danon disease is clinically characterized by the triad of cardiomyopathy, skeletal myopathy and intellectual impairment (1). As both skeletal myopathy and intellectual impairment are usually mild, it is the extent and severity of cardiomyopathy that predominates the clinical progress and determines the outcome. Electric conduction abnormalities are also common, followed by preexcitation with Wolff-Parkinson-White (WPW) syndrome and arrhythmias (6). Other symptoms that are less prevalent include hepatic disease $(1,3)$, retinal disease $(7,8)$ and pulmonary disease (3).

Danon disease has an aggressive course; however, it may be unnoticed or misdiagnosed in the early stages. Boucek et al (6) 
reported that the respective mean age at first symptoms, cardiac transplant and death was 11.7, 20.8 and 20.1 years in males, and $26.8,32.3$, and 40.2 years in females. The most recent systematic review of Danon disease revealed that $34.9 \%$ of patients experienced death or received a heart transplant or ventricular assist devices (9). Therefore, patients with Danon disease must be distinguished from patients with myocardial hypertrophy, such as PRKAG2 syndrome and Fabry disease, which are glycogen storage diseases that also clinically lead to cardiac hypertrophy and electrophysiologic abnormalities (10), and hypertrophic cardiomyopathy (HCM) with sarcomere protein mutations.

The objective of the present study was to identify the clinical and molecular characteristics of Danon disease and to compare the clinical, electrocardiographic (ECG) and echocardiographic features of patients with Danon disease with those of patients with the PRKAG2 syndrome, Fabry disease and sarcomere protein mutation.

\section{Materials and methods}

Study population. An exon and boarding intron analysis of 96 cardio disease-associated genes (Table SI) was performed in 770 patients with HCM using second-generation sequencing (11) at the HCM clinic in the Department of Ultrasound, Xijing Hospital (Xi'an, China) between May 2012 and February 2020. The identified mutations were confirmed in family members of the probands and 300 healthy controls. A total of seven patients with LAMP2 mutation and their families were included in the present study. Furthermore, 5 patients with the PRKAG2 mutations, 8 patients with galactosidase A mutations and 12 patients with sarcomere protein mutations were among the 770 patients with HCM, and they were compared with the patients with Danon disease. All participants who were evaluated provided written informed consent. All investigations were conducted in compliance with the principles of the Declaration of Helsinki and were approved by the ethics committee of Xijing Hospital, Fourth Military Medical University (Xi'an, China). For participants aged $<16$ years, written informed consent was obtained from the parents.

All measurements were made to coincide with the guidelines of the European Society of Cardiology (12). HCM was defined by a maximal left ventricular (LV) wall thickness (MLVWT) of $\geq 15 \mathrm{~mm}$ in adults and $\geq 13 \mathrm{~mm}$ in first-degree relatives, excluding those that may be explained solely by loading conditions or the patient being an athlete. If the patient was aged $<18$ years, the diagnosis of HCM was made based on MLVWT $>2$ SD than the predicted mean ( $\mathrm{z}$-score $\geq 2$, where a $\mathrm{z}$-score is defined as the number of standard deviations from the population mean). Patients with hypertension, coronary artery disease, aortic coarctation, congenital or valvular heart disease, metabolic disorder or athlete's heart were excluded.

ECG. Standard 12-lead ECG was recorded prior to or after the echocardiographic examination. Ventricular preexcitation was characterized by short PR intervals (PR $<120 \mathrm{msec}$ ) and/or initial QRS slurring (delta wave) during the sinus rhythm. LV voltage was reported as the $S$ wave in $V_{1}$ plus the maximal $\mathrm{R}$ wave in $\mathrm{V}_{5}$ or $\mathrm{V}_{6}\left(\mathrm{~S}_{\mathrm{V} 1}+\mathrm{R}_{\mathrm{V} 5}\right.$ or $\left.\mathrm{R}_{\mathrm{V} 6}\right)$, according to the Sokolow-Lyon criteria (13).

Transthoracic echocardiography (TTE). TTE was performed using the Philips iE33 ultrasound system (Philips Medical Systems) and the EPIQ 7C Ultrasound System (Philips Medical Systems). The patients were placed in the left lateral position as if undergoing a routine echocardiographic study. The ECG was recorded simultaneously. Hypertrophied LV segments were identified from two-dimensional echocardiographic images according to the American Heart Association 17-segment model (14). Asymmetric hypertrophy indicated that the ratio between the interventricular septum thickness (IVS) and LV posterior wall thickness (LVPW) was $>1.3$. MLVWT was defined as the greatest dimension at any site within the LV myocardium. All echocardiographic measurements, including left atrial (LA) dimensions, LV ejection fraction (LVEF) and LV outflow tract (LVOT) gradient, were determined according to guidelines from the American Society of Echocardiography and the European Association of Cardiovascular Imaging (14). Furthermore, the early diastolic peak velocities of mitral inflow (E) and the late diastolic peak velocities of mitral inflow (A) and mitral annulus (e') were measured. Then, the E/e' ratio and the E/A ratio were calculated to evaluate LV diastolic function (15).

Cardiac magnetic resonance (CMR). CMR examinations were performed using a 1.5-T CMR imaging system (Magnetom Aera; Siemens AG). All images were acquired with ECG-gating and during repeated breath-hold conditions. The presence and amount of scarring were assessed using phase-sensitive late gadolinium enhancement CMR (LGE-CMR). T1-weighted inversion-recovery imaging was performed to assess LGE $10 \mathrm{~min}$ after the administration of $0.2 \mathrm{mmol} / \mathrm{kg}$ contrast medium (Dotarem; Guerbet).

Genetic analysis. A genetic analysis was performed as previously described (11). In brief, peripheral blood leucocytes were extracted from patients. Primers were designed to amplify the coding exons of 96 cardio disease-associated genes. The identified mutation was further confirmed by bidirectional Sanger sequencing among the remaining family members and 300 healthy unrelated individuals with normal ECG and echocardiographic findings and without any family history of cardiovascular disease.

Statistical analysis. Statistical analysis was performed with SPSS version 20 (IBM Corp.). Categorical variables were expressed as n (\%) and Fisher's exact test was used to compare these variables between groups. Continuous variables were expressed as the mean \pm SD and differences between groups were compared using Student's t-test or analysis of variance. For multiple comparisons, Tamhane T2 or Bonferroni's post hoc test were performed. $\mathrm{P} \leq 0.05$ was considered to indicate a statistically significant difference.

\section{Results}

Clinical presentation. Among the 770 patients with HCM, seven Danon patients were identified $(0.9 \%)$ and 5 of them 
Table I. Clinical, demographic and genetic data of patients with Danon disease.

\begin{tabular}{|c|c|c|c|c|c|c|c|}
\hline Item & $\begin{array}{l}\text { Family F1 } \\
\text { III-9 }\end{array}$ & $\begin{array}{l}\text { Family F2 } \\
\text { III-2 }\end{array}$ & $\begin{array}{c}\text { Family F3 } \\
\text { III-3 }\end{array}$ & $\begin{array}{l}\text { Family F4 } \\
\text { III-3 }\end{array}$ & $\begin{array}{l}\text { Family F5 } \\
\text { III-1 }\end{array}$ & $\begin{array}{l}\text { Family F6 } \\
\text { III-2 }\end{array}$ & $\begin{array}{l}\text { Family F7 } \\
\text { III-8 }\end{array}$ \\
\hline Sex & Male & Female & Male & Male & Male & Male & Female \\
\hline Age at diagnosis & 11 years & 3 years & 12 years & 20 years & 6 months & 1 year & 23 years \\
\hline History of sudden death ${ }^{c}$ & - & + & - & - & - & - & - \\
\hline History of syncope ${ }^{\mathrm{d}}$ & + & - & - & - & - & - & - \\
\hline SBP/DBP (mmHg) & $86 / 54$ & a & a & $134 / 62$ & a & a & $110 / 71$ \\
\hline Clinical presentation & $\begin{array}{l}\text { Chest } \\
\text { tightness }\end{array}$ & Tachypnea & $\begin{array}{l}\text { Chest pain, } \\
\text { troponin }\end{array}$ & None & Angeioma & None & $\begin{array}{l}\text { Fatigue, chest } \\
\text { tightness, } \\
\text { breathlessness }\end{array}$ \\
\hline NYHA class & $\mathrm{I}$ & $\mathrm{I}$ & $\mathrm{I}$ & $\mathrm{I}$ & $\mathrm{I}$ & $\mathrm{I}$ & III \\
\hline Arrhythmia & Normal & $\begin{array}{c}\text { Sinus } \\
\text { tachycardia }\end{array}$ & Normal & $\begin{array}{l}\text { Second-degree } \\
\text { AV block and } \\
\text { WPW }\end{array}$ & WPW & Normal & $\begin{array}{l}\text { Premature } \\
\text { ventricular } \\
\text { contraction }\end{array}$ \\
\hline $\mathrm{S}_{\mathrm{V} 1}+\mathrm{R}_{\mathrm{V} 5}$ or $\mathrm{R}_{\mathrm{V} 6}(\mathrm{mV})$ & 4 & 2.1 & 10.4 & 6.3 & 9.3 & 7 & 1.20 \\
\hline RV1 (mV) & 1.2 & 0.97 & 2.1 & 0.31 & 3.78 & 5.2 & 0.1 \\
\hline Heart rate (bpm) & 79 & 117 & 67 & 45 & 108 & 97 & 86 \\
\hline $\mathrm{LA}(\mathrm{mm})$ & 22 & 24 & 30 & 43 & 13 & 18 & 40 \\
\hline MLVWT (mm) & 14 & 17 & 25 & 18 & 16 & 15 & 8 \\
\hline $\operatorname{LVEF}(\%)$ & 67 & 86 & 67 & 40 & 61 & 76 & 20.6 \\
\hline $\mathrm{E} / \mathrm{e}^{\prime}$ ratio & a & a & 15.4 & 39.3 & 16.3 & 20.9 & 41.3 \\
\hline $\mathrm{E} / \mathrm{A}$ ratio & $>1$ & $>1$ & $>1$ & $>2$ & $>1$ & $>1$ & $>2$ \\
\hline SAM & - & + & - & - & + & - & - \\
\hline LVOT-PG (mmHg) & 4 & 90 & 6 & 27 & 7 & 14 & 1 \\
\hline Skeletal myopathy & $\mathrm{b}$ & $\mathrm{b}$ & b & Yes & $\mathrm{b}$ & $\mathrm{b}$ & b \\
\hline Ocular manifestation & b & b & No & b & $\mathrm{b}$ & $\mathrm{b}$ & b \\
\hline Cognitive impairment & No & $\mathrm{b}$ & No & No & b & b & b \\
\hline Genetic analysis & $\begin{array}{l}\text { c. } 388 G>A \\
(p . E 130 K)\end{array}$ & $\begin{array}{l}\text { c.959A>G } \\
(\text { p.Y320C) }\end{array}$ & $\begin{array}{l}\text { c.779-782del } \\
\text { (p.H260fs) }\end{array}$ & $\begin{array}{l}\text { c. } 928 G>A \\
(p . V 310 I)\end{array}$ & $\begin{array}{l}\text { c.121delT } \\
\text { (p.C41Afs) }\end{array}$ & $\begin{array}{c}\text { c.750delA } \\
(\text { p.V251Lfs*32) }\end{array}$ & $\begin{array}{c}\text { c.1054delG } \\
(\mathrm{p} . \mathrm{V} 352 \mathrm{Ffs} * 5)\end{array}$ \\
\hline Treatment with blocker & None & Metoprolol & Bisoprolol & None & Metoprolol & None & Bisoprolol \\
\hline Pacemaker implantation & None & None & None & CRT-P & None & None & None \\
\hline
\end{tabular}

${ }^{a}$ Lack of relevant information; ${ }^{b}$ lack of assessment; ${ }^{c}$ Within pedigree; ${ }^{d}$ In the patient and not within pedigree. SBP, systolic blood pressure; DBP, diastolic blood pressure; NYHA, New York Heart Association functional class; WPW, Wolff-Parkinson-White syndrome; AV, atrioventricular; LA, left atrium; MLVWT, maximal left ventricular wall thickness; LVEF, left ventricular ejection fraction; E/e' ratio, ratio of the early diastolic peak velocities of mitral inflow and mitral annulus; E/A ratio, ratio of early-to-late mitral inflow velocities; SAM, systolic anterior motion; LVOT, left ventricular outflow tract; PG, peak gradient; CRT-P, cardiac resynchronization therapy with pacemaker.

were male (71\%; Table I and Fig. 1). A total of three patients were diagnosed at an early age ( 6 months, 1 and 3 years of age, respectively). Of the patients with Danon disease, 2 patients were asymptomatic and 4 had variable clinical presentations, including chest pain, chest tightness, breathlessness and fatigue. The proband (III-1) of family F5 was diagnosed incidentally when he was in the hospital to cure a head hemangioma. Furthermore, one patient had poor cardiac function and was classified as New York Heart Association Class III (16) and the cardiac function of other 6 patients were essentially normal.

The surface 12-lead ECGs were abnormal with a high voltage (average of $\mathrm{S}_{\mathrm{V} 1}+\mathrm{R}_{\mathrm{V} 5}$ or $\mathrm{R}_{\mathrm{V} 6}=5.76 \mathrm{mV}$; Table $\mathrm{I}$ ). Furthermore, two patients had a ventricular preexcitation pattern (WPW pattern) with a short PR interval and one patient had a second-degree atrial ventricular block. Furthermore, four patients presented with a fragmented $\mathrm{QRS}$ complex (fQRS) on their surface ECG.

All patients had an HCM phenotype on presentation with a mean MLVWT of $17 \mathrm{~mm}$ (range, 14-24 mm; Table I). Furthermore, one patient had mild skeletal myopathy. A total of three patients underwent cognitive assessment and no cognitive impairment was determined.

Genetic analysis. Each of the seven patients was identified with one mutation in the LAMP2 gene (Table I and Fig. 2). Among the mutations, five were novel mutations, one mutation (c.928G $>$ A) had previously been reported (17) and one mutation had been reported as a pathogenic mutation previously ClinVar (Aug 09, 2013; https://www.ncbi.nlm.nih. gov/clinvar/variation/179062/) but had not been reported in 


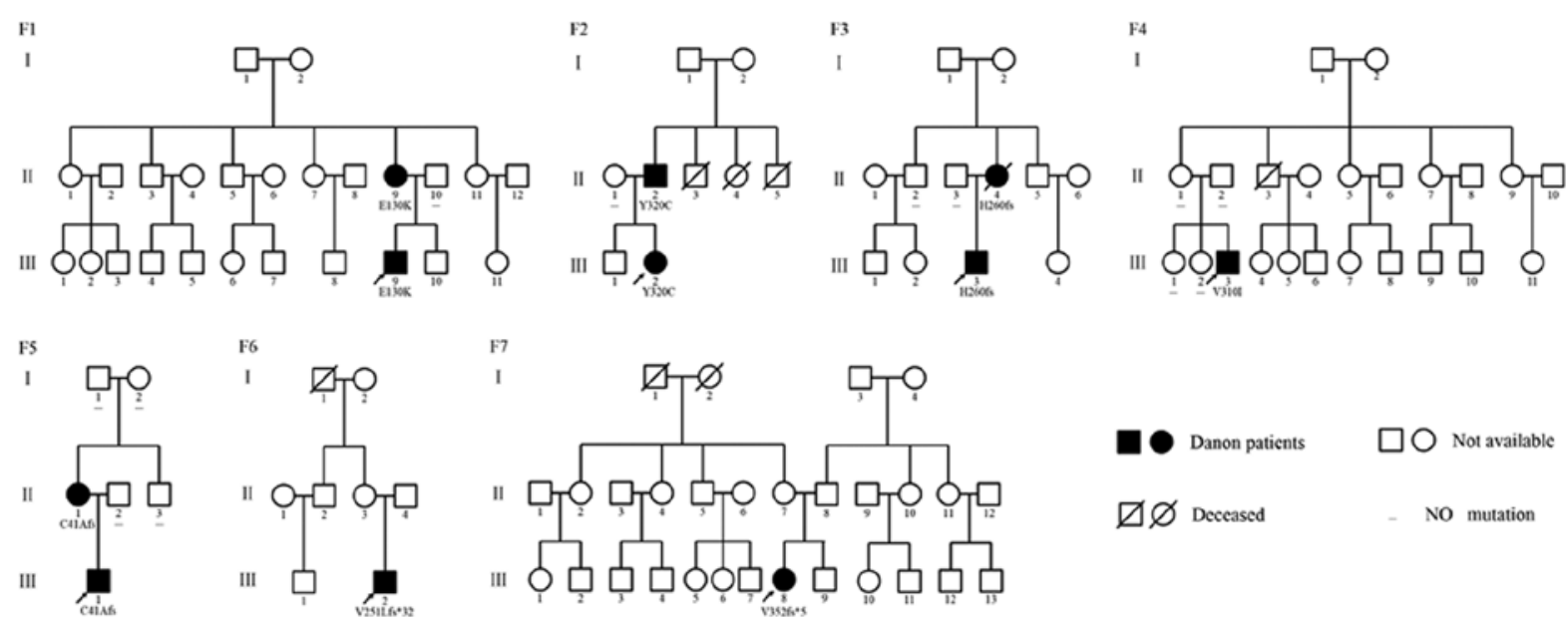

Figure 1. Pedigree of families F1-F7 with phenotypic and genotypic information. The squares indicate male members; the circles indicate female members; the solid symbols represent the individuals diagnosed with Danon and the open symbols represent the unavailable individuals. The probands are marked with an arrow. The genotype for individuals is noted below the symbol, where available. '-' indicates the absence of mutations.

individuals or large population studies. In total, three mutations were point mutations and four were frameshift mutations. Regarding their occurrence in the pedigrees, four mutations were detected in one of their parents, one mutation was a de novo mutation and two mutations were not confirmed in their pedigree because their parents were not available.

Comparison with other patients with HCM. Compared with 5 patients with the PRKAG2 mutation (Table II), patients with Danon disease presented at an earlier age (10 \pm 9 years vs. $34 \pm 10$ years, $\mathrm{P}=0.001)$, had a smaller LA size $(27 \pm 11 \mathrm{~mm}$ vs. $41 \pm 6 \mathrm{~mm}, \mathrm{P}=0.033)$, a thinner MLVWT $(16 \pm 5 \mathrm{~mm}$ vs. $35 \pm 6 \mathrm{~mm}, \mathrm{P}<0.001)$ and a lower probability of pacemaker implantation $(\mathrm{P}=0.010)$. Compared with 8 patients with Fabry disease (Table II), patients with Danon disease also presented at an earlier age $(10 \pm 9$ years vs. $42 \pm 8$ years, $\mathrm{P}<0.001)$, had a smaller LA size $(27 \pm 11 \mathrm{~mm}$ vs. $39 \pm 6 \mathrm{~mm}, \mathrm{P}=0.036)$ and a thinner IVS $(16 \pm 5 \mathrm{~mm}$ vs. $24 \pm 6 \mathrm{~mm}, \mathrm{P}=0.036)$.

After excluding the 3 youngest patients with Danon disease, the 4 remaining patients (Family F1 III-9, Family F3 III-3, Family F4 III-3, Family F7 III-8) were compared with sexand age-matched HCM patients with sarcomere-protein mutations by one-to-three matching (Table III). The 4 Danon patients exhibited a lower LVOT gradient $(12 \pm 12 \mathrm{mmHg}$ vs. $47 \pm 35 \mathrm{mmHg}, \mathrm{P}=0.009)$ and worse diastolic function (E/e': $32 \pm 14$ vs. $16 \pm 7, \mathrm{P}=0.013$ ). Danon patients presented with concentric LV hypertrophy on MRI and late gadolinium enhancement revealed diffused abnormal enhancement (Fig. 3A and B). HCM patients with sarcomere-protein mutations presented with asymmetric hypertrophy on MRI and late gadolinium enhancement indicated spotted abnormal enhancement (Fig. 3C and D).

Case report. The proband (III-3) of family F3 came to our HCM center (Xijing Hospital, Xi'an, China) at the age of 12 years (May, 2014) with complaints of chest tightness and pectoralgia during exercise along with elevated troponin (Trop). His ECG exhibited sinus irregularity with a high voltage (RV5 + SV1=12.2 mV; Fig. 4A). Echocardiography indicated a particularly increased IVS $(25 \mathrm{~mm})$ and LVPW
(20 mm; Fig. 4A), preserved LVEF (65\%), and normal LVOT gradient $(6 \mathrm{mmHg})$ and diastolic function $\left(\mathrm{E} / \mathrm{e}^{\prime}=15.4\right)$. The proband's laboratory findings included myocardial damage [troponin T (TropT), $15.93 \mathrm{ng} / \mathrm{ml}$; myoglobin (Mb), $366.9 \mathrm{ng} / \mathrm{ml}$; creatine kinase isoenzyme $\mathrm{MB}$ (CK-MB), $7.9 \mathrm{ng} / \mathrm{ml}$ ] and hepatic lesions [alanine aminotransferase (ALT), $246 \mathrm{IU} /$; aspartate aminotransferase (AST), 241 IU/1; alkaline phosphatase (ALP), 249 IU/1]. A further liver biopsy revealed mild fatty change and lipofuscin in certain hepatic cells. The patient was advised to continue hospitalization for medical treatment and was administered irbesartan tablets, bisoprolol, polyene phosphatidylcholine capsules and risuvastatin calcium tablets. Magnetic resonance imaging assessment confirmed massive LV hypertrophy [LV anterior wall (LVAW), $30 \mathrm{~mm}$; LV lateral wall, $34 \mathrm{~mm}$; IVS, 18-20 mm; Fig. 3A]. Late gadolinium enhancement revealed focal changes in the thickened subendocardial IVS and diffused abnormal enhancement in the subendocardial anterior and lateral wall (Fig. 3B), which suggested metabolic disease.

From July 2015 to Oct. 2017, the patient's ECG indicated gradually shortening PR intervals (from 134 to $104 \mathrm{msec}$ ) and gradually wider QRS durations (from 100 to $144 \mathrm{msec}$ ) with delta waves resembling the WPW pattern. The ECG also exhibited fQRS in the V3 lead and in additional limb leads (V3-V5; Fig. 4B-D). Echocardiography exhibited an increased thickness of the basal IVS (from 14 to $37 \mathrm{~mm}$ ) and basal LVAW (from 16 to $39 \mathrm{~mm}$; Fig. 4B-D), damaged diastolic function (E/e' from 15.4 to 21.0) and preserved LVEF. The proband was prescribed valsartan, metoprolol, hydrochlorothiazide and coenzyme Q10.

In Jan. 2018, the patient had palpitations and chest tightness after eating rich food or overeating. ECG indicated intraventricular block with fQRS in limb leads (V3-V6) and chest leads (I, aVL; Fig. 4E). The thickness of basal IVS had increased to $47 \mathrm{~mm}$ (Fig. 4E). Echocardiography revealed still preserved LVEF (65\%) but damaged E/e' (26.0), along with LVOT obstruction (LVOTO) with a gradient of $20 \mathrm{mmHg}$. The patient's laboratory findings also indicated increased levels of transaminases, ALP, TropT, Mb and CK-MB (ALT, 230 IU/1; AST, 288 IU/1; ALP, $261 \mathrm{IU} / 1$; TropT, $10.283 \mathrm{ng} / \mathrm{ml}$; 


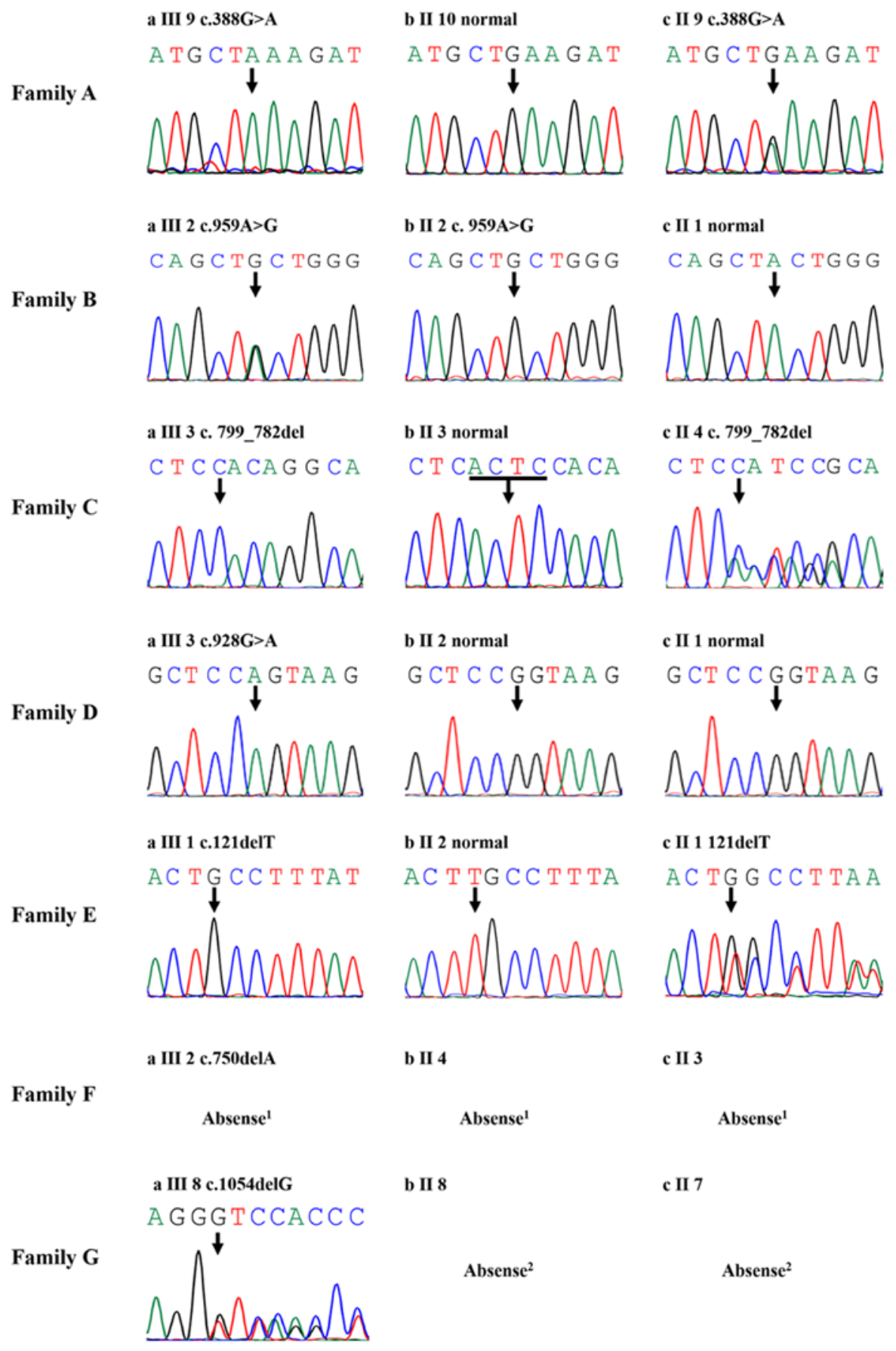

Figure 2. Sequencing analysis of the lysosomal-associated membrane protein 2 gene in families F1-F7. Absence: ${ }^{1}$ Lack of sufficient blood samples for this family and loss to follow-up; ${ }^{2}$ Lack of sufficient blood samples of the proband's parents.

$\mathrm{Mb}, 279.80 \mathrm{ng} / \mathrm{ml}$; CK-MB, $11.700 \mathrm{ng} / \mathrm{ml})$. The patient was additionally administered with carvedilol, nicorandil and silibinin.

\section{Discussion}

Danon disease is a rare clinical syndrome and its true prevalence remains to be determined. In HCM patients, the prevalence ranges from 1 to $6 \%$ (18-21). In individuals with both unexplained LV hypertrophy (LVH) and preexcitation, the prevalence increases to $17-30 \%(20,22)$. The present study reported on 7 patients with a LAMP2 gene mutation identified among $770 \mathrm{HCM}$ patients $(0.9 \%)$. The observed prevalence was essentially in agreement with that reported by previous studies, but there appeared to be a downward trend. Most of the patients in the present study were under 18 years of age and children may be more likely to visit a hospital specializing in children's diseases rather than a general hospital such as ours. This may partly contribute to the slightly reduced prevalence.

D'souza et al (23) reported that the average age of symptom onset of frameshift and missense mutations in male patients was $12.1 \pm 8.4$ and $47.6 \pm 19.1$ years, respectively, and the average age of symptom onset of frameshift mutations in female patients was $21.6 \pm 11.9$ years (no record for female patients with missense mutation). In the present study, however, one male patient with a missense mutation presented 
Table II. Clinical characteristics of patients with Danon disease and PRKAG2.

\begin{tabular}{|c|c|c|c|c|c|}
\hline Item & Danon disease $(n=7)$ & PRKAG2 disease $(n=5)$ & P-value & Fabry disease $(n=8)$ & P-value \\
\hline Age at diagnosis (years) & $10 \pm 9$ & $34 \pm 10$ & 0.001 & $42 \pm 8$ & $<0.001$ \\
\hline Male sex $(\%)$ & $5(71.4)$ & $5(100)$ & 0.470 & $7(87.5)$ & 0.569 \\
\hline History of SCD (\%) & $1(14.3)$ & $1(20)$ & 1.000 & $1(12.5)$ & 1.000 \\
\hline History of syncope (\%) & $1(14.3)$ & $4(80)$ & 0.072 & $2(25.0)$ & 1.000 \\
\hline Pacemaker implantation $(\%)$ & $0(0)$ & $4(80)$ & 0.010 & $1(12.5)$ & 1.000 \\
\hline LA size $(\mathrm{mm})$ & $27 \pm 11$ & $41 \pm 6$ & 0.033 & $39 \pm 6$ & 0.036 \\
\hline MLVWT (mm) & $16 \pm 5$ & $35 \pm 6$ & $<0.001$ & $24 \pm 6$ & 0.036 \\
\hline $\operatorname{LVEF}(\%)$ & $60 \pm 22$ & $48 \pm 13$ & 0.605 & $63 \pm 7$ & 0.983 \\
\hline LVOT-PG (mmHg) & $22 \pm 30$ & $4 \pm 2$ & 0.756 & $41 \pm 65$ & 0.991 \\
\hline LVEDD (mm) & $40 \pm 15$ & $47 \pm 11$ & 0.844 & $21 \pm 4$ & 1.000 \\
\hline SAM (mm) & $2(28.6)$ & $1(20)$ & 1.000 & $4(50.0)$ & 0.592 \\
\hline
\end{tabular}

Values are expressed as $\mathrm{n}(\%)$ or the mean \pm standard deviation. P-values pertain to comparison with Danon disease. Categorical variables were compared using Fisher's exact test and continuous variables were compared using analysis of variance. Multiple-comparison tests to compare LVEF and LVOT were performed with Tamhane T2; all others were performed with Bonferroni's post hoc test. SCD, sudden death of cardiac disease; LA, left atrium; MLVWT, maximal left ventricular wall thickness; LVEF, left ventricular ejection fraction; LVOT, left ventricular outflow tract; PG, peak gradient; LVEDD, left ventricular end-diastolic dimension; SAM, systolic anterior motion; PRKAG2, protein kinase AMP-activated non-catalytic subunit $\gamma 2$.

Table III. Clinical characteristics of patients with Danon disease and patients with sarcomere-protein mutations.

\begin{tabular}{lccc}
\hline Item & Danon $(\mathrm{n}=4)^{\mathrm{a}}$ & Sarcomere-protein mutations $(\mathrm{n}=12)$ & P-value \\
\hline Male sex & $3(75)$ & $9(75)$ & 1.000 \\
Age at diagnosis (years) & $17 \pm 6$ & $47 \pm 5$ & 0.935 \\
History of syncope & $1(25)$ & $74 \pm 9$ & 0.443 \\
Heart rate (bpm) & $69 \pm 18$ & $96 \pm 11$ & 0.353 \\
QRS duration (msec) & $116 \pm 36$ & $132 \pm 25$ & 0.301 \\
PR interval (msec) & $149 \pm 37$ & $4.25 \pm 1.32$ & 0.577 \\
$\mathrm{~S}_{\mathrm{V} 1}+\mathrm{R}_{\mathrm{V} 5}$ or $\mathrm{R}_{\mathrm{V} 6}(\mathrm{mV})$ & $5.48 \pm 3.88$ & $32 \pm 7$ & 0.701 \\
LA size (mm) & $34 \pm 10$ & $65 \pm 5$ & 0.250 \\
LVEF $(\%)$ & $49 \pm 23$ & $16 \pm 7$ & 0.013 \\
E/e' ratio & $32 \pm 14$ & $47 \pm 35$ & $38 \pm 3$ \\
LVOT-PG (mmHg) & $12 \pm 12$ & $25 \pm 8$ & 0.009 \\
LVEDD (mm) & $50 \pm 13$ & $9 \pm 2$ & 0.194 \\
IVS (mm) & $16 \pm 7$ & $8(66.7)$ & 0.063 \\
LVPW (mm) & $14 \pm 6$ & 0.203 \\
SAM & $0(0)$ & 0.077 \\
\hline
\end{tabular}

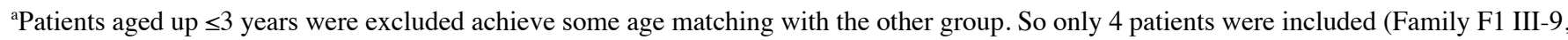
Family F3 III-3, Family F4 III-3, Family F7 III-8). Values are expressed as n (\%) or the mean \pm standard deviation. Categorical variables were compared using Fisher's exact test and continuous variables were compared using Student's t-test. LA, left atrium; LVEF, left ventricular ejection fraction; E/e' ratio, ratio of the early diastolic peak velocities of mitral inflow and mitral annulus; LVOT, left ventricular outflow tract; PG, peak gradient; LVEDD, left ventricular end-diastolic dimension; IVS, interventricular septum thickness; LVPW, left ventricular posterior wall thickness; SAM, systolic anterior motion.

with chest tightness at 11 years of age, which was much earlier than the average age of symptom onset reported by the above study of 47.6 years. Furthermore, two asymptomatic patients were coincidentally identified to have a frameshift mutation prior to their first birthday. These differences may be partly explained by screening at an earlier age. However, patients with more severe pathogenic mutations may exhibit symptoms at a younger age. It is noteworthy that genetic tests and analyses should be provided to identify Danon patients at an earlier age.

Danon disease is an X-linked dominant disorder with a clinical profile that differs by gender. Boucek et al (6) reported 
A

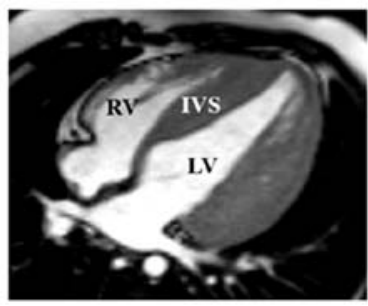

C

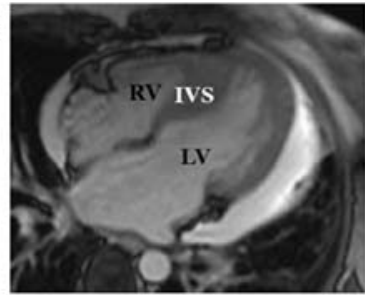

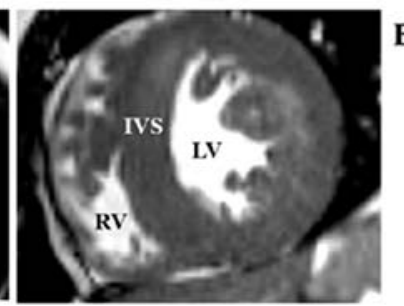

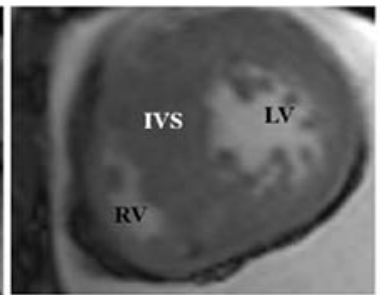

B
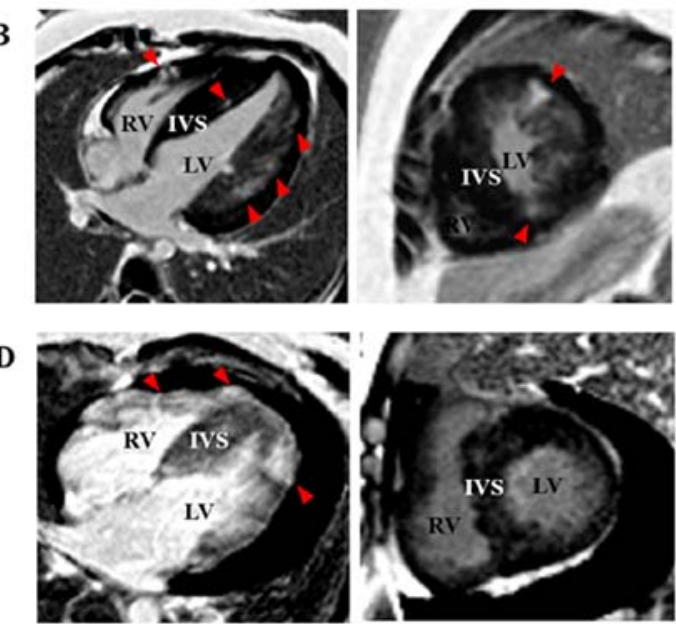

Figure 3. Representative CMR images. Left image represents four-chamber view, whilst the right image represents the short axis view of left ventricle. (A) CMR of patients with Danon disease. (B) Delay-enhancement CMR of patients with Danon disease. (C) CMR of HCM patients with sarcomere-protein mutations. (D) Delay-enhancement of HCM patients with sarcomere-protein mutations. Red triangles indicate enhancement in subendocardial myopathy. $\mathrm{LV}$, left ventricle; RV, right ventricle; IVS, intraventricular septum; CMR, cardiac magnetic resonance.

A

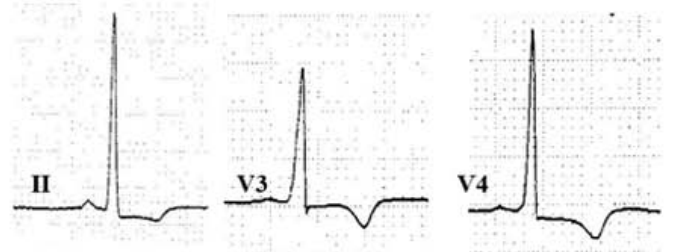

B

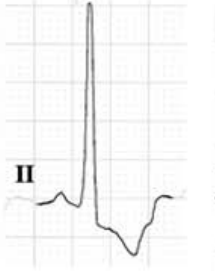

C

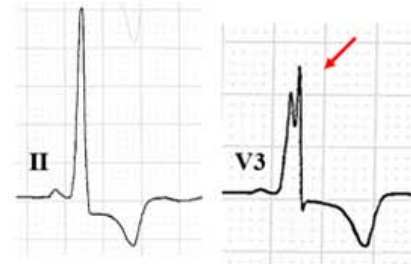

D
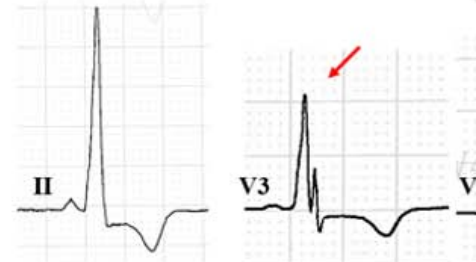

$\mathbf{E}$

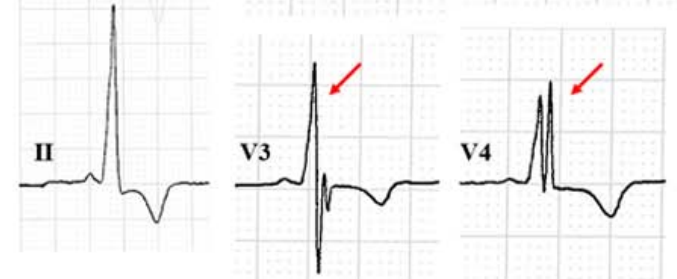

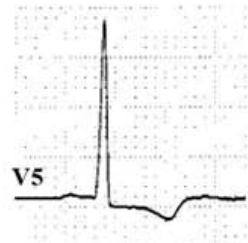
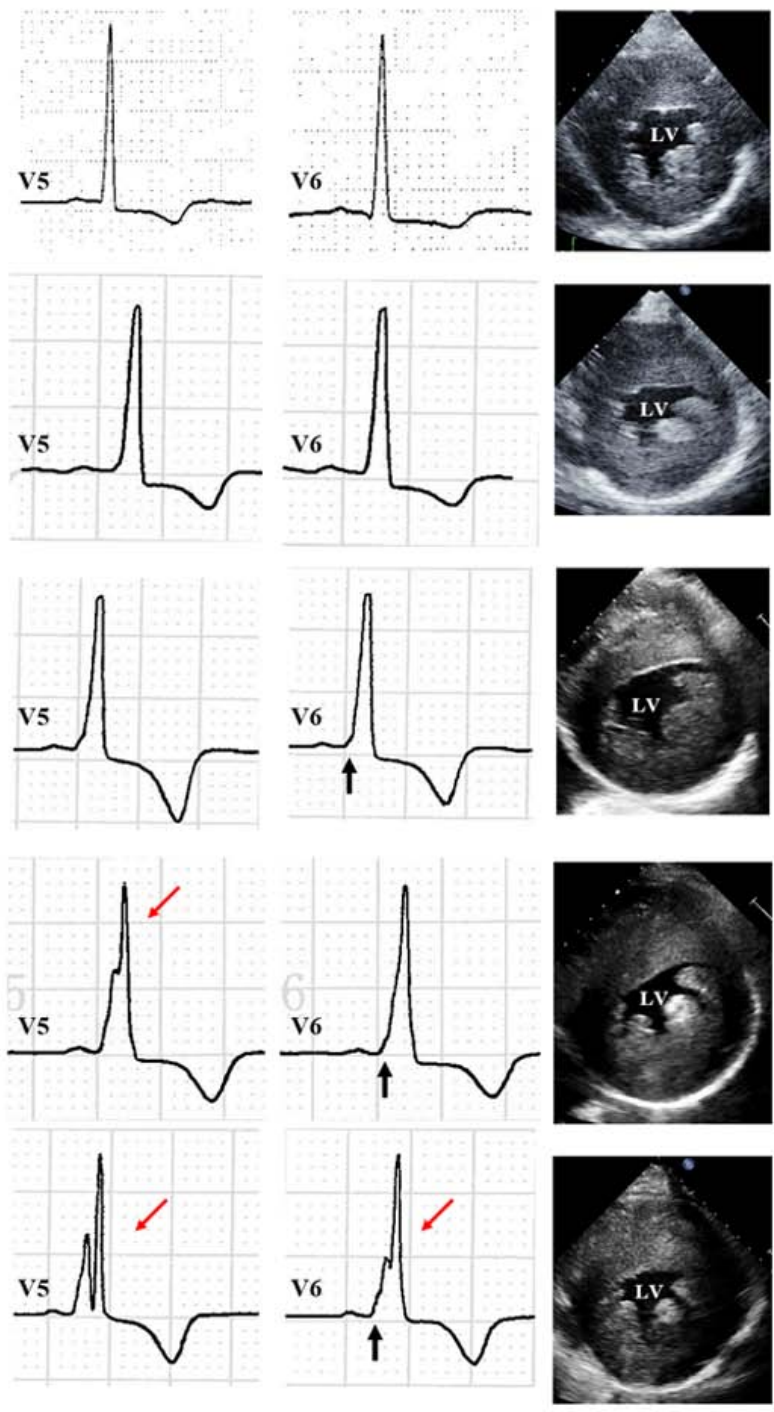

Figure 4. Representative 12-lead electrocardiogram and echocardiography images of patient F3 III-3 during follow-up. (A) In May 2014. (B) In July 2015. (C) In Aug 2016. (D) In July 2017. (E) In Jan 2018. In each panel, the images from left to right represent limb II (5 mm/mV, $25 \mathrm{~mm} / \mathrm{msec}), 1 \mathrm{mb}$ V3-V6 $(2.5 \mathrm{~mm} / \mathrm{mV}, 25 \mathrm{~mm} / \mathrm{msec})$ in 12-lead electrocardiogram and the short axis view of left ventricular in echocardiography, respectively. Black arrow, delta wave. Red arrow, fragment QRS complex. LV, left ventricle. 
that the mean age of first symptoms in males was $12.1 \pm 6.8$ years, while that in females was 15 years later at $27.9 \pm 14.5$ years. It is difficult to determine the age at onset in adult female patients due to the insidious nature of the disease (24). However, cases of female patients with childhood onset have also been described in a number of studies $(18,25-29)$. In addition to a later symptom onset, females are thought to have a relatively mild clinical phenotype $(6,23)$. In the present study, the proband of Family F2 exhibited tachypnea and mitral regurgitation at the age of 3 years and had LVH and LVOTO with systolic anterior motion. Of note, in the proband's father, who was 36 years old, the disease was not as severe. Myocardial biopsy and laboratory examination may be helpful to explain LAMP2 protein function, but they did not receive these relevant examinations. The course of their disease will be further monitored.

An fQRS on surface ECG reflects myocardial scarring and abnormal conduction (30). It may be used as an indirect marker to predict the presence of fibrosis (31) and has been associated with severe arrhythmic events and poor prognosis in HCM $(32,33)$. The patients of the present study who presented with fQRS on surface ECG (57\%) had an average age of $\sim 11$ years, which was much earlier than that reported in a previous review on patients with HCM (32). It may be hypothesized that hypertrophic muscle fibers and increased interstitial collagen content due to glycogen deposition may contribute to the earlier and more severe fibrosis present in Danon disease. The histopathology of the myocardium and skeletal muscle in rats with LAMP deficiency (LAMP2 $2^{\mathrm{y} /}$ ) displayed muscle fiber disarray and interstitial fibrosis (34), supporting this theory.

Arad et al (20) reported that Danon patients had a thicker MLVWT compared with patients with PRKAG2 and patients with HCM and sarcomere protein mutation. However, in the present study, Danon patients presented with a thinner MLVWT than patients with PRKAG2. Furthermore, patients with Danon disease also had a thinner MLVWT than patients with Fabry disease. This may be owing to diagnosis of Danon patients at a younger age, compared with patient with PRKAG2 syndrome and Fabry disease. They may also be linked to the clinical features of Danon disease. Danon disease has an aggressive progression in males and the present case report also supports this notion. The MLVWT of the proband of Family F3 increased from 25 to $47 \mathrm{~mm}$ over a 4-year period. In normal Chinese adolescents with BSA similar to this patient (BSA, 1.30-1.66), the MLVWT is stable and $\sim 7 \mathrm{~mm}$ (35). In addition, the average age of the seven Danon patients was 10 years and the data when they first came to our center were selected to make comparisons with patients with PRKAG2 syndrome and Fabry disease. At that time, their LV thickness may not have progressed to a severe stage. In addition, the number of patients with Danon disease in the present study was relatively small, which may have affected the results. Patients with Danon disease and patients with HCM were also compared and it was indicated that patients with Danon disease had a worse diastolic function than patients with HCM. However, the difference in IVS was not statistically significant.

There are four limitations to the present study. First, only a small number of Danon patients were included. This may have influenced the estimation of the prevalence of Danon disease in HCM. Furthermore, the study did not examine the association between the type of mutation and the clinical presentation. Secondly, three Danon patients in our study were too young and two of them had been discovered coincidentally. This may influenced the results of comparison between Danon patients and other disease. Thirdly, the present study focused on the clinical symptoms of cardiomyopathy and failed to completely evaluate extracardiac manifestations, e.g. by cognitive evaluation and laboratory examinations. At last, certain patients with Danon disease did not receive muscle biopsy. Our group will continue to recruit further Danon patients and add comprehensive examinations in the future.

In conclusion, the present study reported on early-onset attack of Danon disease in 5 males and 2 females with characteristic preexcitation and fQRS on ECG. The present study provided a comprehensive assessment to distinguish between patients with Danon disease and other patients with HCM may provide valuable information for early diagnosis and treatment.

\section{Acknowledgements}

Not applicable.

\section{Funding}

This study was supported by International Cooperation Funding of the China Science and Technology Ministry (grant no. 2014DFA31980), the National Natural Science Foundation of China (grant nos. 81471197 and 81901755), the Key Program of Shaanxi Province (grant no. 2017ZDXM-SF-058), the Key R\&D Project of Shaanxi Province (grant no. 2019KW-076), the Xijing Funded Project for New Technologies and Services (grant no. 417432A) and the Key Science and Technology Innovation Team Project of Shaanxi Province (grant no. 2014KCT-20).

\section{Availability of data and materials}

The datasets used and/or analyzed during the current study are available from the corresponding author on reasonable request.

\section{Authors' contributions}

XYW, BW and XLZ conceived and designed the study. XYW, ZLM, YL, CHL QLY and XLZ were responsible for the acquisition and analysis of the data. DH, ZRL and LWL were responsible for the analysis and interpretation of the data. All authors substantially contributed to the revision of the manuscript, and read and approved the final manuscript.

\section{Ethics approval and consent to participate}

All study procedures in this study were approved by the Ethics Committee of Xijing Hospital, Fourth Military Medical University (Xi'an, China). All patients provided written informed consent form prior to participation in the study. For participants aged $<16$ years, written informed consent was obtained from the parents.

\section{Patient consent for publication}

Not applicable. 


\section{Competing interests}

The authors declare that they have no competing interests.

\section{References}

1. Danon MJ, Oh SJ, DiMauro S, Manaligod JR, Eastwood A, Naidu S and Schliselfeld LH: Lysosomal glycogen storage disease with normal acid maltase. Neurology 31: 51-57, 1981.

2. Nishino I, Fu J, Tanji K, Yamada T, Shimojo S, Koori T, Mora M, Riggs JE, Oh SJ, Koga Y, et al: Primary LAMP-2 deficiency causes X-linked vacuolar cardiomyopathy and myopathy (Danon disease). Nature 406: 906-910, 2000.

3. Tanaka Y, Guhde G, Suter A, Eskelinen EL, Hartmann D, Lüllmann-Rauch R, Janssen PM, Blanz J, von Figura K and Saftig P: Accumulation of autophagic vacuoles and cardiomyopathy in LAMP-2-deficient mice. Nature 406: 902-906, 2000.

4. Eskelinen E, Illert AL, Tanaka Y, Schwarzmann G, Blanz J, Von Figura K and Saftig P: Role of LAMP-2 in lysosome biogenesis and autophagy. Mol Biol Cell 13: 3355-3368, 2002.

5. Arad M: Cardiac Danon disease: Insights and challenges. Int J Cardiol 245: 211-212, 2017.

6. Boucek D, Jirikowic J and Taylor M: Natural history of Danon disease. Genet Med 13: 563-568, 2011.

7. Lee JJ, Ishihara K, Notomi S, Efstathiou NE, Ueta T, Maidana D, Chen X, Iesato Y, Caligiana A and Vavvas DG: Lysosome-associated membrane protein-2 deficiency increases the risk of reactive oxygen species-induced ferroptosis in retinal pigment epithelial cells. Biochem Biophys Res Commun 521: 414-419, 2020.

8. Thompson DA, Constable PA, Liasis A, Walters B and Esteban MT: The Physiology of the retinal pigment epithelium in Danon disease. Retina 36: 629-638, 2016.

9. Brambatti M, Caspi O, Maolo A, Koshi E, Greenberg B, Taylor MRG and Adler ED: Danon disease: Gender differences in presentation and outcomes. Int J Cardiol 286: 92-98, 2019.

10. Sweet ME, Mestroni L and Taylor MRG: Genetic infiltrative cardiomyopathies. Heart Fail Clin 14: 215-224, 2018.

11. Wang L, Zuo L, Hu J, Shao H, Lei C, Qi W, Liu Y, Miao Y, Ma X, Huang CL, et al: Dual LQT1 and HCM phenotypes associated with tetrad heterozygous mutations in KCNQ1, MYH7, MYLK2, and TMEM70 genes in a three-generation Chinese family. Europace 18: 602-609, 2016.

12. Authors/Task Force members, Elliott PM, Anastasakis A, Borger MA, Borggrefe M, Cecchi F, Charron P, Hagege AA, Lafont A, Limongelli G, et al: 2014 ESC Guidelines on diagnosis and management of hypertrophic cardiomyopathy: The task force for the diagnosis and management of hypertrophic cardiomyopathy of the European Society of Cardiology (ESC). Eur Heart J 35: 2733-2779, 2014.

13. Sokolow M and Lyon TP: The ventricular complex in left ventricular hypertrophy as obtained by unipolar precordial and limb leads. Am Heart J 37: 161-186, 1949.

14. Lang RM, Badano LP, Mor-Avi V, Afilalo J, Armstrong A, Ernande L, Flachskampf FA, Foster E, Goldstein SA, Kuznetsova T, et al: Recommendations for cardiac chamber quantification by echocardiography in adults: An update from the American Society of Echocardiography and the European Association of Cardiovascular Imaging. J Am Soc Echocardiogr 28: 1-39.e14, 2015.

15. Nagueh SF, Appleton CP, Gillebert TC, Marino PN, Oh JK, Smiseth OA, Waggoner AD, Flachskampf FA, Pellikka PA and Evangelista A: Recommendations for the evaluation of left ventricular diastolic function by echocardiography. J Am Soc Echocardiogr 22: 107-133, 2009.

16. Martin D, Arthur C, Richard G, Levin RI; Criteria Committee, Devereaux RP, et al: Nomenclature and Criteria for Diagnosis of Diseases of Heart and great vessels. 9th edition. Little Brown, Boston, MA, 1994.

17. Gourzi P, Pantou MP, Gkouziouta A, Kaklamanis L, Tsiapras D, Zygouri C, Constantoulakis P, Adamopoulos S and Degiannis D: A new phenotype of severe dilated cardiomyopathy associated with a mutation in the LAMP2 gene previously known to cause hypertrophic cardiomyopathy in the context of Danon disease. Eur J Med Genet 62: 77-80, 2019.

18. Yang Z, McMahon CJ, Smith LR, Bersola J, Adesina AM, Breinholt JP, Kearney DL, Dreyer WJ, Denfield SW, Price JF, et al: Danon disease as an underrecognized cause of hypertrophic cardiomyopathy in children. Circulation 112: 1612-1617, 2005.
19. Charron P, Villard E, Sébillon P, Laforêt $P$, Maisonobe T, Duboscq-Bidot L, Romero N, Drouin-Garraud V, Frébourg T, Richard P, et al: Danon's disease as a cause of hypertrophic cardiomyopathy: A systematic survey. Heart 90: 842-846, 2004.

20. Arad M, Maron BJ, Gorham JM, Johnson WH Jr, Saul JP, Perez-Atayde AR, Spirito P, Wright GB, Kanter RJ, Seidman CE and Seidman JG: Glycogen storage diseases presenting as hypertrophic cardiomyopathy. N Engl J Med 352: 362-372, 2005

21. Cheng Z, Cui Q, Tian Z, Xie H, Chen L, Fang L, Zhu K and Fang Q: Danon disease as a cause of concentric left ventricular hypertrophy in patients who underwent endomyocardial biopsy. Eur Heart J 33: 649-656, 2012.

22. Liu Y, Chen X, Wang F, Liang Y, Deng H, Liao H, Zhang Q, Zhang B, Zhan X, Fang X, et al: Prevalence and clinical characteristics of Danon disease among patients with left ventricular hypertrophy and concomitant electrocardiographic preexcitation. Mol Genet Genomic Med 7: e638, 2019.

23. D'souza RS, Levandowski C, Slavov D, Graw SL, Allen LA, Adler E, Mestroni L and Taylor MR: Danon disease: Clinical features, evaluation, and management. Circ Heart Fail 7: 843-849, 2014.

24. Sugie K, Komaki H, Eura N, Shiota T, Onoue K, Tsukaguchi H, Minami N, Ogawa M, Kiriyama T, Kataoka H, et al: A nationwide survey on Danon disease in Japan. Int J Mol Sci 19: 3507, 2018.

25. Hedberg Oldfors C, Máthé G, Thomson K, Tulinius M, Karason K, Östman-Smith I and Oldfors A: Early onset cardiomyopathy in females with Danon disease. Neuromuscul Disord 25: 493-501, 2015.

26. Maron BJ, Roberts WC, Arad M, Haas TS, Spirito P, Wright GB, Almquist AK, Baffa JM, Saul JP and Ho CY: Clinical outcome and phenotypic expression in LAMP2 cardiomyopathy. JAMA 301: 1253-1259, 2009

27. Miani D, Taylor M, Mestroni L, D'Aurizio F, Finato N, Fanin M, Brigido S and Proclemer A: Sudden death associated with Danon disease in women. Am J Cardiol 109: 406-411, 2012.

28. Dara BS, Rusconi PG and Fishman JE: Danon disease: Characteristic late gadolinium enhancement pattern on cardiac magnetic resonance imaging. Cardiol Young 21: 707-709, 2011.

29. Kim H, Cho A, Lim BC, Kim MJ, Kim KJ, Nishino I, Hwang YS and Chae JH: A 13-year-old girl with proximal weakness and hypertrophic cardiomyopathy with Danon disease. Muscle Nerve 41: 879-882, 2010.

30. Ogura S, Nakamura $\mathrm{K}$, Morita $\mathrm{H}$, Toh $\mathrm{N}$, Nakagawa $\mathrm{K}$, Yoshida M, Watanabe A, Nishii N, Miyoshi T and Ito H: New appearance of fragmented QRS as a predictor of ventricular arrhythmic events in patients with hypertrophic cardiomyopathy. Circ J 84: 487-494, 2020

31. Ratheendran AC, Subramanian M, Bhanu DK, Prabhu MA, Kannan R, Natarajan KU, Saritha Sekhar S, Thachathodiyil R, Harikrishnan MS and Pai PG: Fragmented QRS on electrocardiography as a predictor of myocardial scar in patients with hypertrophic cardiomyopathy. Acta Cardiol 75: 42-46, 2020.

32. Rattanawong $\mathrm{P}$, Riangwiwat $\mathrm{T}$, Kanitsoraphan $\mathrm{C}$, Chongsathidkiet P, Kanjanahattakij N, Vutthikraivit W and Chung EH: Baseline fragmented QRS increases the risk of major arrhythmic events in hypertrophic cardiomyopathy: Systematic review and meta-analysis. Ann Noninvasive Electrocardiol 23: e12533, 2018

33. Özyılmaz S, Akgül Ö, Uyarel H, Pusuroğlu H, Karayakalı M, Gül M, Çetin M, Satılmışoğlu H, Yıldırım A and Bakır I: Assessment of the association between the presence of fragmented QRS and the predicted risk score of suddena cardiac death at 5 years in patients with hypertrophic cardiomyopathy. Anatol J Cardiol 18: 54-61, 2017.

34. Ma S, Zhang M, Zhang S, Wang J, Zhou X, Guo G, Wang L, Wang M, Peng Z, Guo C, et al: Characterisation of Lamp2-deficient rats for potential new animal model of Danon disease. Sci Rep 8: 6932, 2018.

35. Xu N, Bei X, Zhou W, He X-Z, Tao H-W amd Liu X: New reference values for echocardiography dimensions of 800 healthy Chinese infants and children. Chinese J Med Ultrasound (electronic edition) 1: 40-49, 2012.

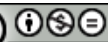

This work is licensed under a Creative Commons Attribution-NonCommercial-NoDerivatives 4.0 International (CC BY-NC-ND 4.0) License. 